\title{
Empirical Study on the Mobile App-Aided College English Vocabulary Teaching
}

\author{
Yuan Yuan
}

\begin{abstract}
The paper aims at analyzing how to improve College English vocabulary teaching with the aid of a Mobile App. The research objects are 60 freshmen of non-English majors from two classes of a provincial medical university in Mainland China. Based on the contrast of vocabulary tests results between the control group and the experimental group, the author analyzes the influences of a Mobile App aid on College English vocabulary teaching. The main findings of this research can be listed as follows: students' pronunciation performances of required vocabulary in experimental group are much better than those of the control group; vocabulary spelling of students with the Mobile App aid learning is more accurate than that of those without the Mobile App aid; the experimental group students identify the meanings of required vocabulary more effectively than the control group students; the experimental group students tend to apply more newly-learned vocabulary required in the designed task. The results gained are of great methodological significance in the vocabulary teaching and learning.
\end{abstract}

Index Terms - College English, English vocabulary, mobile apps, vocabulary teaching.

\section{INTRODUCTION}

Vocabulary is one of the three major elements of one language and the basic material of one language [1]. English vocabulary teaching is an indispensible part and also a necessary and fundamental link of English teaching [2]. English vocabulary is also a major element of English learning and English communication. The correct understanding and mastery of English vocabulary is the basis of learning English well. One cannot learn English well without English vocabulary learning. Accurately speaking, English vocabulary mastery is the basis of improving one's English comprehensive abilities in listening, reading, writing and translating or interpreting. Therefore, more attention should be paid to English vocabulary teaching and learning.

The Curriculum Orientation of Guidelines on College English Teaching in Mainland China (2014) specifies that college English is the most important part of college foreign language education, and that college English is a fundamental compulsory course for most non-English major undergraduates. College English teaching objectives are aimed to foster students' comprehensive and practical English abilities, especially their communicative skills and learning autonomy so that students can make full use of English in proficient ways to conduct effective communication in their later work and social interactions, to

Manuscript received August 5, 2018; revised October 12, 2018.

Yuan Yuan is with English Department, Anhui Medical University, China (e-mail: shirleyyuan0921@163.com). enrich their cultural quality for better personal development and international communication. According to Guidelines on College English Teaching (2014), college or university students are required to master a vocabulary of about 5500 words and 1000 phrases to meet the basic requirements, among which 2000 are active words or phrases, and to make full use of them in proficient ways both in speaking and in writing. However, it seems that vocabulary is a hard nut for Chinese students. On one hand, in daily teaching most Chinese English teachers assume that remembering new words is just students' own affaire, so they haven't paid enough attention to the vocabulary teaching; on the other hand, students just try their best to remember new words by rote, although they can remember words at that time, they seldom find occasions to use words so new words quickly slip from their mind. As a result, almost all students think that they are at loss how to grasp words effectively, and limitation of words has thus discouraged them from reading, writing, speaking and translating or interpreting.

A Mobile App, as defined by Wikipedia [3], is a computer program designed to run on a mobile device such as a mobile phone. The term "app" is a shortening of the term "software application"[3]. It has become very popular, and in 2010 was listed as "Word of the Year" by the American Dialect Society [4]. In 2009, technology columnist David Pogue said that newer smart phones could be nicknamed "app phones" to distinguish them from earlier less-sophisticated smart phones [5]. Usage of mobile apps has become increasingly prevalent across mobile phone users [6]. A May 2012 comScore study reported that during the previous quarter, more mobile subscribers used apps than browsed the web for different purposes on their devices: $51.1 \%$ vs. $49.8 \%$ respectively [7]. For example, Jenny Eppard, Omaima, and Preeya Reddy (2016) conducted a research on the application of Mobile Apps in the English Language Classroom [8]. Guo Nenghui (2016) also studied the application of Mobile Apps in the adult English teaching [9]. The latest report from American Zenith (2017) said that the global subscribers of smart mobile phones have been steadily increased by the year of 2018 among which Chinese subscribers have added up to 1.3 billion[10]. It is investigated that every undergraduate in Anhui Medical University has a smart phone which can help them easily download needed Mobile Apps. The Guidelines on College English Teaching (2014) has also pointed out that college English teaching modes should be innovated with the rapid development of the information technology by applying up-dated technology tools such as Mobile Apps. There are several popular Mobile Apps for vocabulary learning in China, such as Baicizhan, Shanbei, Leci, Hujiang etc. Therefore, there is an easy and convenient access to English vocabulary teaching and learning by Mobile Apps. However, 
it is not so frequent and common to do the research especially in combination of Mobile apps with English vocabulary teaching in the context of Chinese foreign language classroom. This essay will investigate the influence of the Mobile App aid on college English vocabulary teaching.

\section{THEORETICAL BASIS}

\section{A. Ebbinghaus Memory Law}

Ebbinghaus, as described by Wikipedia [11], is known for his discovery of the forgetting curve, and he is also the first person to describe the learning curve [11]. After repeated tests and with concluded data, he depicted the famous forgetting curve that revealed the memory law, as is shown in Fig. 1.

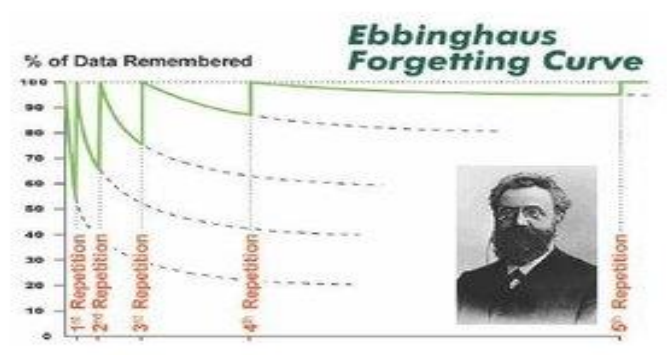

Fig.1. Ebbinghaus forgetting curve.

The forgetting curve indicates the decline of memory retention in time, and also describes the exponential loss of information that one has learned when there is no attempt to retain it [11]. Fig. 1 clearly shows that data remembered will be gradually decreased without any repetitions whereas data remembered will be greatly increased with more and more repetitions as time goes by. Therefore, it can be inferred that in English vocabulary teaching and learning if there are some attempts to retain the new vocabulary, for example, through increased repetition or rehearsal or reviewing, students' short-term memory of new vocabulary will lead to long-term memory of vocabulary, that is, more vocabularies will be remembered. The Mobile App for English vocabulary learning called Baicizhan adopted in the research was designed on the theoretical theory of Ebbinghaus forgetting curve of memory law [12].

\section{B. Associative Memory}

In psychology, associative memory is defined as the ability to learn and remember the relationship between unrelated items [13]. This type of memory deals specifically with the relationship between different objects or concepts [13]. Cognitive theories emphasize mainly on making knowledge meaningful and helping learners to organizing relate new information to existing knowledge in memory [14]. American memory expert Harry.Laureyin said that the basic law of memory is to associate new information with the known things [15]. Therefore, associative memory is a good way for teachers to instruct learners to adopt. A lot of researches have been done on the influence of associative memory on English vocabulary learning. Xie Yinbao (2012) discussed the design and implementation of English vocabulary associative memory computer-assisted learning system (AM-CALS) which helped students improve their vocabulary memory[16]; Ren Chating\& Gao Dong (2011) analyzed the schema theory of English vocabulary associative memory and pointed out that associative memory was an extremely effective way to learn English vocabulary well [17]. Associative memory not only stimulates students' learning interests but also improves their long-term memory. The Mobile App for English vocabulary learning called Baicizhan adopted in the research was also designed on the theoretical theory of associative memory [12], and the major characteristic of Baicizhan is to associate vocabulary with pictures, videos or hieroglyphic. College English vocabulary is a real headache for Chinese college students to learn. If the teacher can instruct students to learn vocabulary with associative memory, the current hard nut situation will be greatly improved.

\section{RESEARCH DESIGN}

\section{A. Research Problems}

The objective of English vocabulary teaching is the mastery of the pronunciation, spelling, meaning and usages of vocabulary [1]. Therefore, the research aims at investigating the influence of the mobile app-aided college English teaching in terms of the four aspects. In detail, the research questions can be listed as follows:

1) Can students' pronunciation of required vocabulary be more correct with the aid of a Mobile App?

2) Can students' spelling of required vocabulary be more accurate with the aid of a Mobile App?

3) Can students' identifying the meaning of required vocabulary be more effective with the aid of a Mobile App?

4) Can students apply newly-learned vocabulary more autonomously in designed task with the aid of a Mobile App?

\section{B. Research Objects}

60 non-English major freshmen from two classes at Anhui Medical University in Mainland China were randomly selected. The two classes are in different majors. But the students English are at almost the same level with one class of the average score of 117.2 (total score is 150) of English subject in the College Entrance Examination whereas the other class of the average score of 117. 4. 30 students from one class were assigned to the experimental group and 30 students from the other class were assigned to the control group. At the very beginning of the semester, students from two classes were told to learn 150 vocabulary of College English Test Band 4 (CET -4) within the semester of 14 weeks, which are new to all the 60 students by three -round screening.

\section{Research Methods}

A Mobile App called Baicizhan 2015 Android Version was chosen in the research. Baicizhan is a kind of software which is specially designed for English vocabulary learning. The software was designed mainly based on the 
Ebbinghaus's memory law and associative memory. The software provides each English word with its pronunciation, its meaning both in English and in Chinese, example sentences, a picture indicating the meaning of the word, a video relevant to the word, and a hieroglyphic. That is, the software shows an English word to the learners in the form of its sound, shape, meaning and usage. What's more important, the Mobile App provides six different ways in Review Part instead of the same simple repetitions to help learners review and remember vocabulary, which is quite different from the usual way of learning by rote. More than 15,000 words are covered in Baicizhan including required CET-4 vocabulary in the research. Each word is arranged as shown in Fig. 2 and Fig. 3. The six different ways of Review Part of Baicizhan are arranged as shown in Fig. 4.

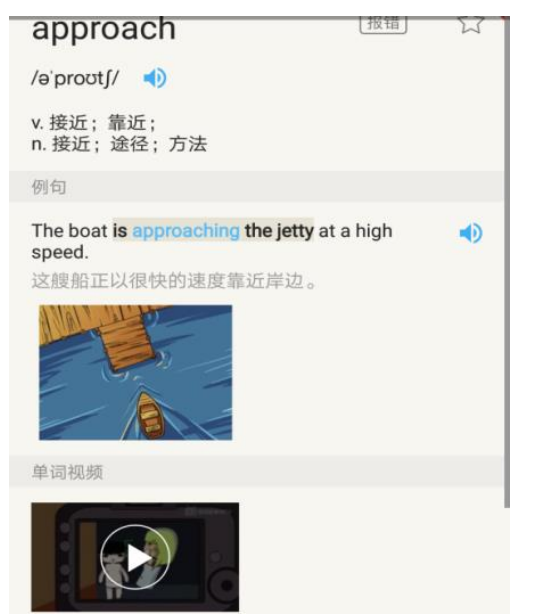

Fig. 2 .Word arrangement in Baicizhan.

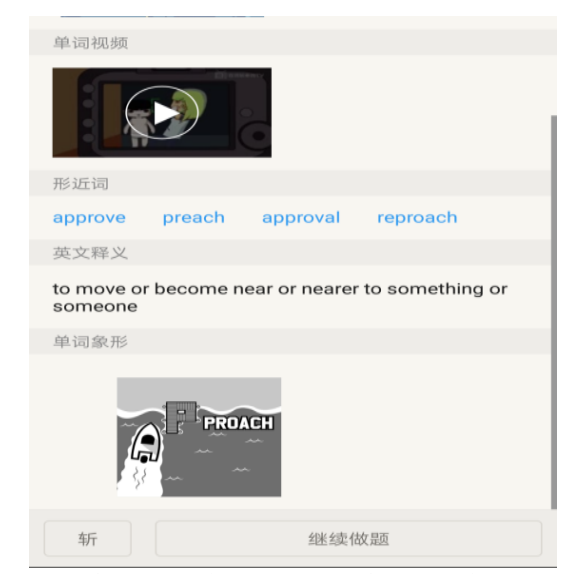

Fig.3. Word arrangement in Baicizhan

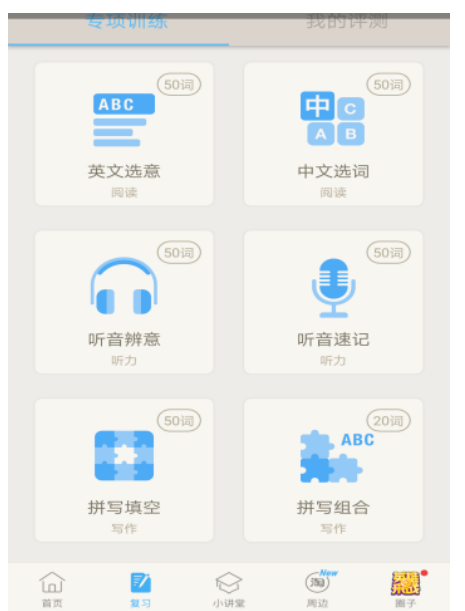

Fig. 4. Review Part arrangement of Baicizhan.
Each student in the experimental group had his own smart mobile phone which could be easily linked to the campus free WIFI. Each student in the experimental group was required to download the software Baicizhan into his smart mobile phone, and then to set up a list of required 150 vocabularies to be learned this semester in Baicizhan. The required 150 vocabularies to be learned were chosen from Integrated Course 1 Student's book, New College English (Second version). The students were supposed to have 70 English lessons within 14 weeks. The new 150 vocabularies, which were included in five articles to be learned respectively, were specifically marked as the vocabulary of CET-4 in Student's Book.

\section{Research Process}

In the experimental class, the students adopted the Mobile Apps-aided teaching mode. The students were instructed to use Baicizhan to learn the required 150 words from sound, shape, Chinese meaning, example sentence, picture, video, English paraphrase, and Hieroglyphic provided by the software adopted. After class, the experimental students were required to continue to learn the vocabulary with the aid of Baicizhan for at least one hour and a half every two days. The experimental students were also required to do the Review Part of Baicizhan repeatedly attempting to change short-term memory vocabulary in class into long-term memory vocabulary after class. The teacher would check on the students' performance every week. In the control class, the students adopted the traditional vocabulary teaching mode. The teacher instructed the students to learn the vocabularies in class. In detail, the students usually read the pronunciation after the teacher for two or three times, then the teacher orally explained the Chinese meaning and the usage if necessary of the vocabulary, and then the teacher asked the students to do sentence translation of the vocabulary both from Chinese into English and from English into Chinese. After class, the teacher didn't give any instructions, the control group students might just do vocabulary learning by rote by themselves without any technological tools, and the teacher wouldn't check on them. The whole semester lasted for 14 weeks. At the end of the semester, all the students were given the same four pieces of tasks: to voice and record the pronunciation of required 150 vocabularies, to have a test on the spelling of required 150 vocabularies, to identify and write down the Chinese meanings of required 150 vocabularies, to write a short but formal passage on a free topic with about 120-180 words without teacher's any reminding of students' using as many newly-learned words as possible. The author analyzed the two classes' variations in the four assigned tasks.

\section{RESULTS AND DISCUSSION}

\section{A. Correctness of Pronunciations of the 150 Vocabularies}

30 experimental group students and 30 control group students recorded their pronunciations of the 150 vocabularies respectively and they were required to email the recordings to the teacher. The author listened to each student's pronunciations of the 150 vocabularies, and noted down the times of correctness and incorrectness of pronunciations, the number of correctly-pronounced 
vocabularies and the number of incorrectly- pronounced vocabularies. The results were as follows in Table I.

TABLE I: NUMBERS OF CORRECTNESS AND INCORRECTNESS OF PRONUNCIATIONS

\begin{tabular}{|c|c|c|c|c|}
\hline & \multicolumn{4}{|c|}{ Pronunciation } \\
\hline & $\begin{array}{l}\text { Total times of } \\
\text { correct } \\
\text { pronunciations }\end{array}$ & $\begin{array}{l}\text { Total times of } \\
\text { incorrect } \\
\text { pronunciations }\end{array}$ & $\begin{array}{l}\text { Total number of } \\
\text { correctly- } \\
\text { pronounced } \\
\text { vocabularies }\end{array}$ & $\begin{array}{l}\text { Total number of } \\
\text { incorrectly- } \\
\text { pronounced } \\
\text { vocabularies }\end{array}$ \\
\hline $\begin{array}{l}\text { The } \\
\text { Experimental } \\
\text { group }\end{array}$ & 4057 & 443 & 134 & 16 \\
\hline $\begin{array}{l}\text { The control } \\
\text { group }\end{array}$ & 2746 & 1754 & 101 & 49 \\
\hline $\begin{array}{l}\text { The balance } \\
\text { number }\end{array}$ & +1311 & -1311 & +33 & -33 \\
\hline
\end{tabular}

The statistics in Table I obviously show that the experimental group students as a whole performed better than the control group students in terms of pronouncing the vocabularies. First, respectively speaking, the students with the aid of the Mobile App Baicizhan pronounced the vocabularies almost 1.5 times more correctly than the students without. The vast majority $(90 \%)$ of the experimental group students gave correct pronunciations whereas the control group students gave $61 \%$ correct pronunciations. What's more, $89 \%$ among the 150 vocabularies were pronounced correctly by the experimental group students, in contrast, $67 \%$ among the 150 vocabularies were pronounced correctly by the control group students. It was also found that both experimental group and control group students performed well in pronouncing shorter vocabulary whereas the experimental group students performed better in terms of longer vocabulary. It is thus indicated that their pronunciation are really improved when college students use the Mobile App Baicizhan to help learn vocabulary.

As for the big difference in the pronunciation, it is discussed that the control group students seldom practiced the pronunciations of the vocabularies after class except the two or three times reading of pronunciation after the teacher in class because most of them admitted that they didn't receive a systematic learning and practice of phonetics during the middle school, thus they didn't know how to pronounce vocabularies by themselves after class. On the other hand, they were unwilling to spend time making full use of $\mathrm{mp} 3$ or CD-Rom to practice their pronunciation after class if the teacher made no any requirement of them. In contrast, although some of the experimental group students didn't learn phonetics before systematically either, they were required to learn with the Mobile App Baicizhan for about one hour and a half every two days, they could repeatedly listen to the pronunciations of vocabularies, imitate the sounds, and until they could pronounce the vocabulary correctly. Enough time and good resources ensure the more correctness of pronunciations of the experimental group students. To sum it up, the experimental group students have done significantly better in learning the sound of vocabularies than the control group students.

\section{B. Accuracy of Spellings of the 150 Vocabularies}

The Chinese meanings of the 150 English vocabularies were arranged on a test paper in random order. All the 60 students were required to write down the spellings of the 150 vocabularies within one hour. The teacher read over the students' spellings, ticked out the accurate ones of the vocabularies, and then counted the number of accurately-spelled vocabularies. The results were as follows in Table II.

TABLE II: NUMBERS OF ACCURACY AND INACCURACY OF SPELLINGS

\begin{tabular}{|l|c|l|l|l|}
\hline & \multicolumn{4}{|c|}{ Spelling } \\
\hline & $\begin{array}{l}\text { Total } \\
\text { times of } \\
\text { accurate } \\
\text { spelling }\end{array}$ & $\begin{array}{l}\text { Total } \\
\text { times of } \\
\text { inaccurate } \\
\text { spelling }\end{array}$ & $\begin{array}{l}\text { Total } \\
\text { number of } \\
\text { accurately } \\
\text {-spelled } \\
\text { vocabularies }\end{array}$ & $\begin{array}{l}\text { Total } \\
\text { number of } \\
\text { inaccurately } \\
\text {-spelled } \\
\text { vocabularies }\end{array}$ \\
\hline $\begin{array}{l}\text { The } \\
\text { Experimenta } \\
\text { group }\end{array}$ & 3619 & 881 & 128 & 22 \\
\hline $\begin{array}{l}\text { The control } \\
\text { group }\end{array}$ & 2487 & 2013 & 97 & 53 \\
\hline $\begin{array}{l}\text { The balance } \\
\text { number }\end{array}$ & +1132 & -1132 & +31 & -31 \\
\hline
\end{tabular}

The statistics in Table II shows that the experimental group students as a whole have done a better job than the control group students in terms of spelling performance. First of all, specifically speaking, the students with the aid of the Mobile App Baicizhan could spell the vocabularies almost 1.3 times more accurately than the students without. Almost $80 \%$ of the experimental group students could give accurate spellings of the 150 vocabularies; in contrast, $55 \%$ of the control group students could give accurate spellings of the 150 vocabularies. What's more, in terms of the number of accurately-spelled vocabularies, the experimental group students accounted for $85 \%$ of the 150 vocabularies whereas the control group only $64 \%$, which is really a big 
gap. To sum it up, the experimental group students have done better in learning the shape of vocabularies than the control group students.

It is discussed that the Review Part of Baicizhan played a major role in the great difference in the accuracy of spelling between the experimental group students and the control group students. The forgetting curve shows that in English vocabulary teaching and learning if there are some attempts to retain the new vocabulary, for example, through increased repetition or rehearsal or reviewing, students' short-term memory of new vocabulary will lead to long-term memory of vocabulary. There are two sections of spelling reviewing in the Review Part of Baicizhan: spelling blank filling and spelling combination. By doing the two sections, the experimental group students could strengthen their spelling memory and spell out the required vocabulary more accurately than the control group students.

\section{Effectiveness of Identifying the Meanings of the 150 Vocabularies}

The 150 English vocabularies were arranged on a test paper in random order. All the 60 students were required to write down the Chinese meanings of the vocabularies within one hour. The teacher read over the vocabulary meanings and ticked out the times of the effectively identified meanings, and then counted out the number of vocabularies effectively identified in meanings. The results were as follows in Table III.

TABLE III: NUMBERS OF EFFECTIVELY AND INEFFECTIVELY IDENTIFIED MEANINGS

\begin{tabular}{|c|c|c|c|c|}
\hline & \multicolumn{5}{|c|}{ Meaning } \\
\hline & $\begin{array}{c}\text { Total times of } \\
\text { effectively } \\
\text { identified } \\
\text { meanings }\end{array}$ & $\begin{array}{c}\text { Total times of } \\
\text { ineffectively } \\
\text { identified meanings }\end{array}$ & $\begin{array}{c}\text { Total number of } \\
\text { vocabularies } \\
\text { effectively identified } \\
\text { in meanings }\end{array}$ & $\begin{array}{c}\text { Total number of } \\
\text { vocabularies } \\
\text { ineffectively } \\
\text { identified in meanings }\end{array}$ \\
\hline $\begin{array}{c}\text { The Experimental } \\
\text { group }\end{array}$ & 4404 & 96 & 142 & 8 \\
\hline The control group & 3157 & 1343 & 96 & 54 \\
\hline The balance number & +1247 & -1247 & +46 & -46 \\
\hline
\end{tabular}

The statistics in Table III clearly shows that the experimental group students performed overwhelmingly more effectively in identifying the Chinese meanings of the 150 vocabularies than the control group students. Statistically speaking, the students with the aid of the Mobile App Baicizhan effectively identified $98 \%$ of the Chinese meanings of the 150 vocabularies, whereas the students without only $70 \%$, which makes a great difference. In terms of the number of vocabularies ineffectively identified in Chinese meanings, there were only 8 vocabularies (about 5\%) which the experimental group students didn't identify and there were 54 vocabularies (about 36\%) which the control group students didn't identify either. To sum it up, the experimental group students have obviously done more excellent performance in grasping the meanings of vocabularies than the control group students.

Obviously there are two factors that can account for the great difference. On one hand, when students use the software to learn the vocabulary for the first time, Baicizhan associates the required vocabulary to be learned with vivid pictures, videos and Hieroglyphic, which greatly helps students memorize the meanings of the required vocabulary; on the other hand, there are two sections concerning rehearsal of the meanings of vocabularies in the Review Part of Baicizhan, one is to choose English vocabulary with given Chinese meaning, the other is to choose Chinese meaning with given English vocabulary. When the students do the two sections, just as the forgetting curve indicates that data remembered will be greatly increased with more repetitions, to great extent, they can further strengthen their memory understanding of the meanings of the required vocabularies.

\section{Autonomous Application of Newly-learned Words in the Writing}

The ultimate purpose of learning vocabularies is to apply them in the practice whether in oral form or in written form. In order to check whether both two groups of students could apply the newly-learned vocabularies within the 14-week semester in the real context, the author designed a piece of writing task for the 60 students. Both the experimental group students and the control group students were required to write a short but formal passage about 120 -180 words on any topic within 30 minutes (that is the requirement of CET-4 writing). The topic was not decided as the same one for a defined topic may limit students' choice of vocabularies. Before writing, the teacher didn't remind the students to use the newly-learned vocabularies this semester in their writing. By reading over the students' writings, the teacher first found out the total number of students applying vocabulary in the writing and then found out all the newly-learned vocabularies used in the students' writings respectively. Any student who applied one or more vocabularies in the writing was counted in the total number of students. The same vocabulary applied several times by different students was regarded as only one vocabulary. The results were as follows in Table IV.

The statistics in Table IV apparently explains that the experimental group students tend to more autonomously apply newly-learned vocabularies in the writing than the control group students. Comparatively speaking, $80 \%$ students from the experimental group have already learned to use newly-learned vocabularies in real context whereas only $57 \%$ students from the control group have learned to 
use newly-learned vocabularies in real context. It is really amazing to find that the two pairs of percentages of the students applying newly-learned vocabularies (80\%VS57\%) are very similar to the two pairs of percentages of the students giving accurate spelling (almost $80 \%$ VS 55\%), which is no wonder that a student may not use a vocabulary in the writing if he hasn't learned it well including its accurate spelling. In addition, the experimental group students applied $71 \%$ of newly-learned vocabularies to the real context writing, in contrast, the control group students applied only $35 \%$ which is the half of the experimental group.

TABLE IV: NUMBERS OF NEWLY-LEARNED VOCABULARIES AUTONOMOUSLY APPLIED IN WRITING

\begin{tabular}{|c|c|c|c|c|}
\hline & \multicolumn{4}{|c|}{ Autonomous application of vocabularies } \\
\hline & $\begin{array}{l}\text { Total } \\
\text { number } \\
\text { of } \\
\text { students } \\
\text { applying } \\
\text { words in } \\
\text { writing }\end{array}$ & $\begin{array}{l}\text { Total } \\
\text { number } \\
\text { of } \\
\text { students } \\
\text { not } \\
\text { applying } \\
\text { words in } \\
\text { writing }\end{array}$ & $\begin{array}{l}\text { Total } \\
\text { number of } \\
\text { newly-lear } \\
\text { ned } \\
\text { vocabulari } \\
\text { es applied }\end{array}$ & $\begin{array}{l}\text { Total } \\
\text { number of } \\
\text { newly-lear } \\
\text { ned } \\
\text { vocabulari } \\
\text { es } \\
\text { unapplied }\end{array}$ \\
\hline $\begin{array}{l}\text { The } \\
\text { Experimen } \\
\text { tal group }\end{array}$ & 24 & 6 & 107 & 43 \\
\hline $\begin{array}{l}\text { The } \\
\text { control } \\
\text { group }\end{array}$ & 11 & 19 & 52 & 98 \\
\hline $\begin{array}{l}\text { The } \\
\text { balance } \\
\text { number }\end{array}$ & +13 & -13 & +55 & -55 \\
\hline
\end{tabular}

It is admitted that the choice of vocabulary whether previously learned or newly learned in the writing is greatly affected by many aspects such as the repertoire of students' vocabulary, the writing topic, or the writing style, etc. To achieve the real autonomy of the students' application of vocabulary in the writing, the teacher in the research didn't give any hints or reminders to require students to apply new-learned vocabulary in their writing. Based on the different performances previously concerning pronunciation, spelling, and identifying meaning, however, there is a tendency that more required vocabularies have come into the long-term-memory of more experimental group students than the control group students, so it is natural that more experimental group students, if not all, have applied more newly-learned vocabularies autonomously in the designed writing. What's more, it is not difficult to find that the experimental group students did the worst in the application of vocabularies than in the pronunciation, spelling, and meaning, although they did better than the control group students, which can be explained that the software Baicizhan hasn't provided any sections of vocabulary applications whether in oral or written form, which may be a weak point in this Mobile app.

\section{CONCLUSION}

This research investigates the influence of the Mobile App Baicizhan aid on the college English vocabulary teaching from the four aspects of vocabulary's pronunciation, spelling, meaning, and autonomous application. The research finds that the students with the aid of the Mobile App Baicizhan in vocabulary teaching have done much better than the students without. The research introduces Mobile Apps into college English vocabulary teaching and learning. Based on the research results, the researcher analyzes how to improve students' vocabulary in terms of sound, shape, meaning, and application. The research is of great methodological significance for enhancing college English vocabulary teaching and improving students' vocabulary learning in Mainland China. However, there are still some points which need further studies. For example, it is necessary to explore more ways to test the autonomy of students' application of newly-learned vocabularies; in addition, the sex differences in the study can also be taken into consideration which may influence the results of the study. What's more, it is also meaningful to investigate how to create more situational occasions for Chinese students to autonomously use their newly-learned vocabulary as possible as they can whether in class or out of class.

\section{REFERENCES}

[1] N. Yue. (2017). Computer multimedia assisted English vocabulary teaching courseware. [Online]. Available: https://doi.org/10.3991/ijet.v12.i12.7955

[2] N. Oktafiani, S. Siska, and M. K. Ikhsan, "An analysis of professional English teacher as facilitator in teaching and learning process a study of English teacher at smpn 1 pantai cermin and mtsn gaduang surian pantai cermin," Physical Review Letters, vol. 94, no. 7, pp. 1-4, 2005.

[3] Wikipedia. [Online]. Available: https://en.wikipedia.org/wiki/Mobile_app

[4] "'App" voted 2010 word of the year by the American Dialect Society (UPDATED) American Dialect Society".

[5] P. David, "A place to put your apps," New York Times, 2013.

[6] L. Sean, "Mobile app usage grows 35\%, TV \& web not so much," 2002.

[7] P. Sarah, "COMscore: In U.S. mobile market, samsung, android top the charts," Apps Overtake Web Browsing, 2012.

[8] J. E. Omaima and P. Reddy. (2016). The next generation of technology: mobile apps in the English language classroom. [Online]. Available: http://dx.doi.org/10.3991/ijet.v11i04.5293

[9] N. Guo, "The application of mobile apps in the adult English teaching," Journal of the College of Northwest Adult Education, vol. 6, pp. 18-20, November 2016.

[10] Mobile.

[Online]. http://mobile.yesky.com/92/383558092.shtm

[11] Hermann_Ebbinghaus. [Online]. https://en.wikipedia.org/wiki/Hermann_Ebbinghaus

[12] VIPCN. [Online]

$$
\text { [Online]. }
$$

https://www.vipcn.com/shoujiruanjian/yueduxuexi/203179.html
[13] Associative_memory. [Online]. Available: https://en.wikipedia.org/wiki/Associative_memory_(psychology)

[14] Cognitivism. [Online]. Available: https://en.wikipedia.org/wiki/Cognitivism_(psychology)

[15] Baike. [Online].

Availa https://baike.so.com/doc/5786397-5999183.html

[16] Y. B. Xie, "Design and implementation of English vocabulary associative memory," Computer Applications and Software, vol.2 9, pp. 213-215, 2012.

[17] R. Chating and G. Dong, "Analysis on the schema theory of English vocabulary associative memory," Journal of Shanxi Teachers University, pp. 90-91, March 2011. 


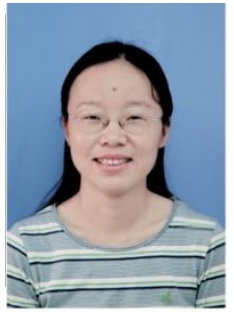

Yuan Yuan was born on 21 September 1974 in Hefei city, Anhui province, China. She graduated from Fuyang Teachers College of Anhui province in China as an undergraduate and received her bachelor degree of arts in the field of English education in 1997. She also graduated from Chinese University of Hong Kong as a postgraduate and received her master degree of arts in the field of applied English linguistics in 2008 in Hong Kong. The author's major field of study is applied English linguistics.
She has been working as a College English teacher in Anhui Medical University since 1997. The previous publications of articles include: "Comparison and Contrast of English language planning and policy for senior secondary education between Mainland China and Hong Kong," Asia-Pacific Edu Res, DOI 10.1007/s40299-012-0043-z, December 2012; "A Corpus-Based Study of the Use of Verb DO in L2 Hong Kong University Students Writing," Overseas English, vol.(4), pp.120-122, February 2012; "Investigation and analysis of corpus application in the college English teaching in Anhui provincial universities," Journal of Hubei University of Economics (Humanities and Social Science), vol.10 No.3, pp.196-197, March 2013. Her current research interests are still in the applied English linguistics focusing on college English teaching. 